\title{
Geniculate hemianopia: incongruous homonymous field defects in two patients with partial lesions of the lateral geniculate nucleus
}

\author{
CARL H. GUNDERSON AND WILLIAM F. HOYT \\ From the Neurology Service, Letterman General Hospital, and the Neuro-Ophthalmology Unit at the \\ University of California School of Medicine, San Francisco, U.S.A.
}

SUMMARY Quantitative perimetric studies in two patients with involvement of a lateral geniculate nucleus (caused by astrocytoma in one and a small arteriovenous malformation in the other) revealed strikingly incongruous defects in the contralateral homonymous fields of vision. The patterns of these hemianopias were analysed and correlated anatomically in terms of established patterns of retinal projections within the six cellular laminae of the geniculate nucleus. Incongruous wedge-shaped field defects recorded in the patient with the astrocytoma are unique and appear to be pathognomonic of focal geniculate disease in the dorsal crest of the nucleus.

The lateral geniculate nucleus (LGN) is an enigma in clinical neuro-ophthalmology. Clinical-anatomical studies correlating patterns of visual field defects and necropsy findings in the LGN have been recorded in only three cases (Henschen, 1898; Mackenzie, Meighan, and Pollock, 1933; and Balado, Malbran, and Franke, 1934) but the characteristics identifying these field defects as geniculate hemianopias were not defined.

This report describes two examples of distinctive and strikingly incongruous geniculate hemianopias caused by an astrocytoma in one patient, and an arteriovenous malformation in the other. The clinical and patho-anatomical significance of the perimetric findings in these cases is discussed in terms of the laminar anatomy of the lateral geniculate nucleus.

PATIENTS

CASE 1 Slowly progressive incongruous left homonymous hemianopia and progressive left hemiplegia in a man with a 19-year history of temporal-lobe epilepsy produced by astrocytoma involving the right $L G N$ and neighbouring structures

At the age of 24 (1949), this member of the Air Force first experienced episodes of staggering and giddiness that

${ }^{1}$ Reprint requests: Professor Hoyt, Department of Neurological Surgery, University of California, San Francisco, California 94122, U.S.A. lasted for several minutes and were preceded by a vague and disturbing premonition. Twelve years later (1961), after a prolonged period without sleep, he had three grand mal seizures. His minor attacks were then recognized as a form of psychomotor epilepsy and he was treated successfully with a daily regimen of primidone (Mysoline ${ }^{\circledR}$ ) and phenytoin (Dilantin ${ }^{\circledR}$ ).

In July 1968, at the age of 43 years, he came to Letterman General Hospital in San Francisco complaining of clumsiness in his left arm and difficulty in reading. $\mathrm{He}$ could not see the left side of words, and could not shift his eyes accurately to the left to start reading the next line of print.

OCULAR FINDINGS His vision was 20/20 in each eye and his pupillary reflexes, eye movements, and ocular fundi, including the optic discs, were normal. Examination of his visual fields showed peculiar, relative, left-sided, horizontal, sector-shaped, incongruous, homonymous field defects (Fig. 1A), which were confirmed by several examiners using the Goldmann hemispheric perimeter.

NEUROLOGICAL EVALUATION The patient had some slowing of rapid alternating movement in the left hand but no other evidence of motor or sensory disturbance. Results of radiographic and encephalographic examinations were normal.

In September 1968 a second brain scan and electroencephalogram as well as a right carotid arteriogram and a pneumoencephalogram showed no evidence of cerebral abnormality.

CLINICAL COURSE The patient's visual field defects 




FIG. 1. Progressive geniculate hemianopia from astrocytoma involving the right lateral geniculate nucleus (case 1).

$A$. The initial visual field defects (July 1968) were relative in density and grossly incongruous in form. In the left temporal field there was a horizontal 'keyhole-shaped' defect and in the right nasal field, a smaller horizontal wedge-shaped defect.

The schematic diagram of the laminae in the right geniculate nucleus (at the top) indicates, in a mid-coronal section, how a lesion at the dorsal crest of the nucleus produces greater involvement of lamina 6 and, correspondingly, a larger visual defect in its 'field of vision' (arrow) (see discussion).

B. By November 1968 the homonymous defects had enlarged and increased in density, particularly along the horizontal meridian.

C. In December 1968, the patient had lost all vision in his left homonymous fields (and had developed mild left hemiparesis).

slowly enlarged and a left hemiparesis gradually worsened (Fig. 1B and C). Repeat echoencephalogram, electroencephalogram, pneumoencephalogram, and carotid arteriogram in November 1968 showed no evidence of tumour.

On Christmas Day 1968 he had an adversive seizure, during which his head and eyes deviated to the right; later that day he had a typical tonic-clonic convulsion.
Afterward he complained of headache, appeared confused, and displayed profound hemiplegia. An electroencephalogram showed generalized slowing and bursts of $3 \mathrm{~Hz}$ activity with shifting preponderance. A carotid arteriogram showed poor filling of the right middle cerebral vessels. During the next week, he developed papilloedema, became comatose, and died on 7 January 1969. 
NEUROPATHOLOGICAL EXAMINATION (by Dr. Nathan Malamud) Gross examination of the formalin-fixed brain (weight $1,575 \mathrm{~g}$ ) showed two seemingly separate foci of tumour. One, measuring $2 \times 2 \times 2.5 \mathrm{~cm}$, was located in the right temporal lobe and had invaded the amygdala; the other, measuring $2 \times 2.8 \times 2.5 \mathrm{~cm}$, involved the right thalamus and had extended into the rostral midbrain and pontine tegmentum (Fig. 2). A grayish 'infiltrated' area joined the two in the region of the LGN.

Microscopically, the tumour was a single diffuse lesion of the basal ganglia, the mesial temporal lobe, the subthalamus, the mesencephalon, and the pontine tegmen-



FIG. 2. Sections of brain in case 1 showing extent of the astrocytoma at death. It arose in the right temporal lobe (lower section), extended through the geniculate region (arrow) and eventually involved the rostral midbrain (upper section) and pons (section on left). tum. It completely replaced the right retrolenticular zone and the area of the right LGN. It consisted of uniform, radiating, elongated cells, closely packed in fascicles: anteriorly, it was almost avascular and contained calcific deposits; posteriorly, in the region of the midbrain and LGN, it was pleomorphic, necrotic, and showed marked collateral hyperplasia. The right hippocampus was minimally involved by tumour but contained signs of neuronal degeneration and glial reaction typical of Ammon's horn sclerosis.

MICROSCOPIC DIAGNOSIS Pilocytic astrocytoma with malignant degeneration, involving the LGN, the mesial portion of the right temporal lobe, the right basal ganglia, and the brain-stem.

CASE 2 Right incongruous hemianopia in a teenager with a discrete angiographically demonstrated arteriovenous malformation in the area of the left $L G N$

This 16 year old Puerto Rican girl carne to the San Francisco General Hospital in June 1969, complaining of mild frontal headache and 'hazy' vision in her right visual field, first noted seven months earlier when she was recovering from a spontaneous subarachnoid haemorrhage.

OCULAR FINDINGS The patient's vision was'20/20 in each eye with correction of her mild myopic refractive error. The pupillary size and reactions were normal. The nasal side of the right optic disc was slightly paler than the corresponding portion of the left disc, but no evidence of hemianopic pupillary akinesia (Wernicke's hemianopic pupillary response) or afferent pupillary defect (Marcus Gunn sign) could be elicited. Visual-field testing with the tangent screen and the Goldmann perimeter showed a relatively dense but grossly incongruous right-sided hemianopia (Fig. 3). The defect in the right eye obliterated all of the temporal field except for $a 10^{\circ}$ central area, which was spared but depressed. The defect in the left eye consisted of an upper nasal quadrantanopia with a sloping inferior border that extended to within $3-4^{\circ}$ of central fixation (Fig. 3).

NEUROLOGICAL EVALUATION The patient was alert, appeared healthy, and had no weakness of her limbs, no reflex asymmetry, and no sensory loss, incoordination, or postural disturbance. Internal carotid arteriograms


FIG. 3. Incongruous geniculate hemianopia in a patient (case 2) with a small arteriovenous malformation involving the area of the left lateral geniculate nucleus (Fig. 4). See description and anatomical analysis in text. 
showed no abnormalities, but vertebral arteriograms showed a discrete arteriovenous malformation, measuring $0.5 \times 0.5 \times 1.0 \mathrm{~cm}$, arising from the trunk of the left posterior cerebral artery in the ambient cistern. This angioma projected upward and laterally from the parent artery into the region of the left LGN (Fig. 4).

CLINICAL COURSE The patient's headaches were mild and seemed unrelated to her geniculate angioma. Neurosurgical management was considered but the risk of increasing her neurological deficit appeared too great. At follow-up clinic visits, one year and one and a half years later, her visual-field defects had not changed and she had no new neurological symptoms.

ANATOMICAL DIAGNOSIS Arteriovenous malformation involving the left LGN.

\section{DISCUSSION}

The incongruity of the geniculate hemianopias exemplified in these case reports is noteworthy clinically and anatomically. Such field defects have been described in the detailed clinical-anatomical studies of Mackenzie, et al. (1933), and Balado, et al. (1934), and in the clinical reports of Smith, Nashold, and Kreshnon (1961), and Fite (1967).
Incongruity of this magnitude from lesions at the level of the LGN contradicts a hallowed axiom of clinical perimetry. Since Henschen's era spanning the turn of the century, it has been accepted that incongruity of homonymous field defects is most pronounced with lesions near the junction of the optic chiasm and tract, and diminishes progressively with more posterior lesions (Kearns and Rucker, 1959). This diagnostic axiom of perimetry had been attributed to a gradual alignment in the optic tract of the crossed and uncrossed visual axons from corresponding retinal areas.

Two principles of the anatomical organization of the LGN provide a logical basis for the occurrence of incongruous homonymous hemianopias from partial geniculate lesions. The first is Minkowski's (1921) landmark discovery that crossed retinal projections terminate in one set of geniculate laminae (laminae 1, 4, and 6), while uncrossed projections terminate in another set (laminae 2, 3, and 5) (Fig. 1). The second is the principle that corresponding 'points' in the two retinae are represented in the LGN in vertically orientated lines or 'columns' of cells from all six laminae. In this manner the 'two-dimensional' (monocular) organization of

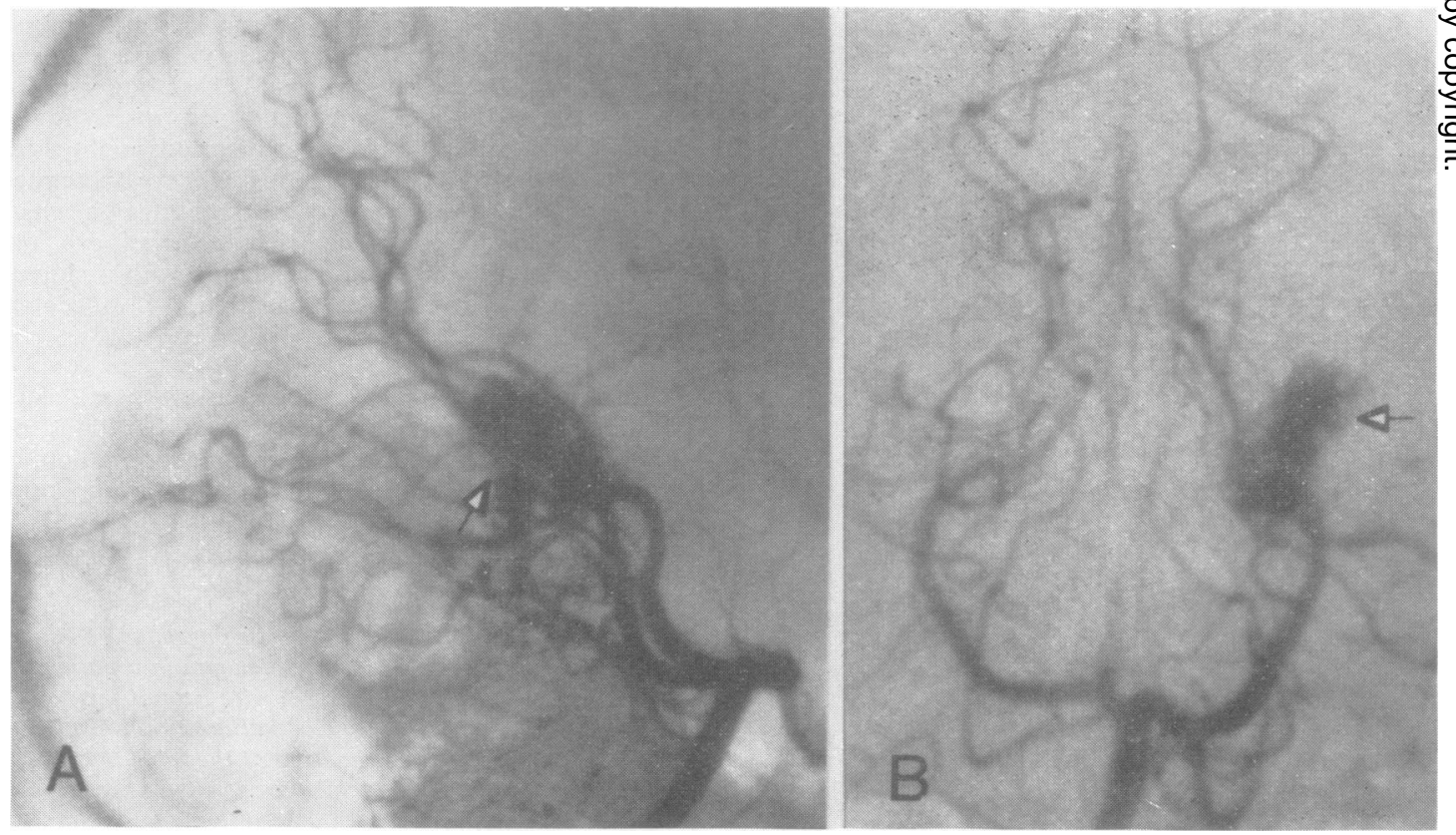

FIG. 4. Arteriovenous malformation in case 2 involving the area of the left lateral geniculate nucleus (arrows) demonstrated in vertebral arteriograms: A. Lateral projection. B. Towne projection. The malformation arises from the left posterior cerebral artery in the ambient cistern and extends posteriorly and laterally in the area corresponding to the base of the geniculate body and pulvinar. 


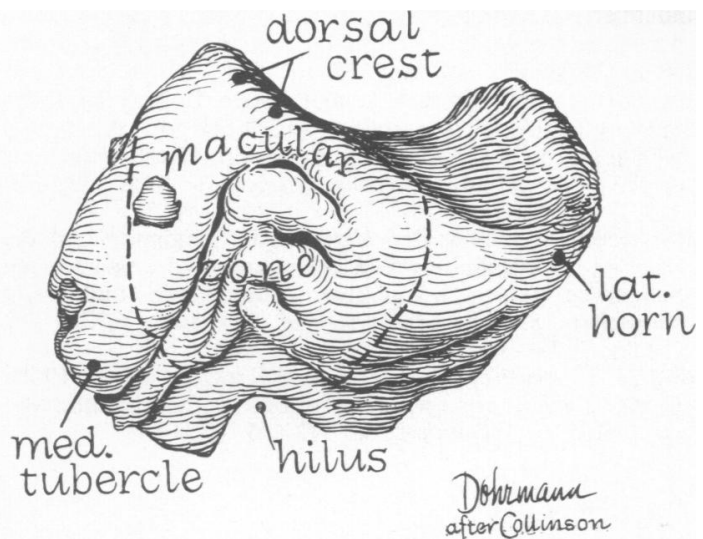

FIG. 5. Diagrams of the right lateral geniculate nucleus. Posterior view of nucleus in man showing its shape, as determined by wax reconstructions (Chacko, 1948), its dorsal crest and the approximate area of its macular zone (dotted line).

rods and cones is transformed into a 'three-dimensional' (binocular) organization of the lateral geniculate neurones, the major portion of which is devoted to 'macular' vision (Brouwer and Zeeman, 1925; Le Gros Clark and Penman, 1934; Kupfer, 1962) (Fig. 5). From these brief remarks concerning principles of crossed and uncrossed retinal projections on the geniculate laminae, it is apparent that irregular or partial involvements of several laminae would produce differing effects in the corresponding homonymous fields of vision.

Neuropathological observations of lateral geniculate destruction from adjacent disease in the thalamus, medial temporal lobe, or brain-stem are relatively frequent. If records of the patient's visual fields are available, they usually indicate total homonymous hemianopia (Lillie, 1930). More subtle changes in the neurones of the LGN are easily overlooked unless the pathologist pays particular attention to this small area of the brain. Lindenberg (1965) illustrated and discussed a variety of vascular (ischaemic) changes in geniculate nuclei including discrete zones of cell necrosis in various laminae. He stressed that compression of the nucleus or occlusion of its vessels can induce selective neuronal death in particular laminae without causing significant alteration in other cellular components of the nucleus (unfortunately no visual field studies had been recorded in his cases) (Lindenberg and Walsh, 1964).

The initial visual field defects depicted in case 1 of this report (Fig. 1A) correlate with selective damage to neurons of laminae 5 and 6 over the dorsal crest of the right LGN. The large central defect in the field of the left eye (Fig. 1A) can be explained by destruction of lamina 6 near the posterior end of the right LGN.Sparing of laminae 4 and 1 would account for the relative nature of the scotoma. More anterior (rostral) involvement of the geniculate crest in non-macular areas would account for the horizontal sector-shaped field defect (Fig. 1A). Penetration into lamina 5 at the geniculate crest caused the smaller defect in the nasal field of the right eye (Fig. 1A). As destruction of the LGN continued, visual defects increased (Fig. 1B). Ultimately, the nucleus was destroyed and the hemianopia became complete (Fig. 1C and Fig. 2).

The grossly incongruous hemianopia in case 2 also can be explained by an incomplete geniculate lesion that caused incongruous 'macular sparing', incongruous superior quadrant defects, and a temporal monocular inferior field defect (right eye) (Fig. 3). The vascular malformation was entwined in the left geniculate nucleus and presumably involved parts of several laminae. The solitary inferior temporal defect in the field of the right eye, unaccompanied by a corresponding defect in the field of the left eye, can be explained by destruction of laminae 4 and 6 where both are fused (here their cells receive projections from the superior part of the retina of the contralateral eye). Greater involvement of the temporal macular field could be explained by involvement of laminae receiving the crossed macular projections (Fig. 3).

In conclusion, the geniculate hemianopias in cases 1 and 2 illustrate the distinctive and markedly incongruous form of the homonymous hemianopias resulting from subtotal geniculate lesions, and exemplify patterns of field defects that can be correlated with the laminar organization in the LGN. Analysis of the unique left-sided hemianopic field defects in case 1 permitted the localization of a lesion in the dorsal crest of the patient's right geniculate nucleus.

\section{REFERENCES}

Balado, M., Malbran, J., and Franke, E. (1934). Incongruencia hemianópsica derecha por lesión primitiva del cuerpo geniculado externo izquierdo (Isópteras internas). Arch. argent. Neurol., 11, 143-151.

Brouwer, B., and Zeeman, W. P. C. (1925). Experimental anatomical investigations concerning the projection of the retina on the primary optic centres in apes. $J$. Neurol. Psychopath., 6, 1-10.

Chacko, L. W. (1948). The laminar pattern of the lateral geniculate body in the primates. J. Neurol. Neurosurg. Psychiat., 11, 211-224.

Clark, W. E. Le Gros, and Penman, G. G. (1934). The projection of the retina in the lateral geniculate body. Proc. roy. Soc. (B), 114, 291-313.

Fite, J. D. (1967). Temporal lobe epilepsy: association with homonymous hemianopsia. Arch. Ophthal., 77, 71-75. 
Henschen, S. E. (1898). Ueber Localisation innerhalb des äusseren Knieganglions. Neurol. Centralbl., 17, 194-199.

Kearns, T. P., and Rucker, C. W. (1959). Clinics in perimetry No. 3.: Incongruous homonymous hemianopsia. Amer. J. Ophth., 47, 317-321.

Kupfer, C. (1962). The projection of the macula in the lateral geniculate nucleus of man. Amer. J. Ophth., 54, 597-609.

Lillie, W. I. (1930). Homonymous hemianopia, primary sign of tumors involving lateral part of the transverse fissure. Amer. J. Ophth., 13, 13-20.

Lindenberg, R. (1965). Neuropathology involving the lateral geniculate bodies, the optic radiation, and the calcarine cortex. In Vol. II, Neuro-ophthalmology Symposium, symposium of the University of Miami and the Baxom Palmer Eye Institute. Pp. 137-166. Edited by J. L. Smith. C. V. Mosby Co: St. Louis.
Lindenberg, R., and Walsh, F. B. (1964). Vascular compressions involving intracranial visual pathways. Trans. Amer. Ophthal. Otolaryng., 68, 677-694.

Mackenzie, I., Meighan, S., and Pollock, E. N. (1933). On the projection of the retinal quadrants on the lateral geniculate bodies, and the relationship of the quadrants to the optic radiations. Trans. ophthal. Soc. U.K., 53, 142169.

Minkowski, M.: Über den Verlauf, die Endigung und die zentrale Repräsentation von gekreuzten und ungekreuzten Sehnerven fasern bei einigen Säugetieren und beim Menschen. Schweiz. Arch. Neurol. Psychiat., 6, 201-252 (1920); 7, 268-303 (1921).

Smith, J. L., Nashold, B. S., Jr., and Kreshon, M. J. (1961). Ocular signs after stereotactic lesions in the pallidum and thalamus. Arch. Ophthal., 65, 532-535. 